\title{
Global propagation features of large-scale traveling ionospheric disturbances during the magnetic storm of 7 10 November 2004
}

\author{
Q. Song ${ }^{1,2}$, F. Ding ${ }^{1}$, W. Wan ${ }^{1}$, B. Ning ${ }^{1}$, and L. Liu ${ }^{1}$ \\ ${ }^{1}$ Beijing National Observatory of Space Environment Institute of Geology and Geophysics, Chinese Academy of Sciences, \\ Beijing 100029, China \\ ${ }^{2}$ Graduate University of Chinese Academy of Sciences, Beijing 100049, China
}

Correspondence to: F. Ding (dingf@mail.iggcas.ac.cn)

Received: 17 June 2011 - Revised: 25 February 2012 - Accepted: 4 April 2012 - Published: 17 April 2012

\begin{abstract}
Larger-scale traveling ionospheric disturbances (LSTIDs) were studied using the total electron content (TEC) data observed from global GPS network in the regions of North America, Europe, and East Asia during the magnetic storm of 7 10 November 2004. 4 LSTID events were detected in North America, 4 in Europe, and 3 in East Asia. The parameters of the 11 LSTID events, such as the propagation azimuth (the angle with respect to north, taking clockwise as positive), horizontal phase velocity and damping rate were determined. Our results showed two new propagation features of the LSTIDs. One was the latitudinal dependence of the LSTIDs' propagation azimuths. The LSTIDs tended to deflect more to west from south as they propagated to lower latitudes, which indicated that the Coriolis force was one of the main causes of the LSTIDs' southwestward deviation. The other was the different mean horizontal phase velocities of LSTIDs among different regions. The mean horizontal phase velocity of LSTIDs was $422 \pm 36 \mathrm{~m} \mathrm{~s}^{-1}$ in North America, $381 \pm 69 \mathrm{~m} \mathrm{~s}^{-1}$ in Europe, and $527 \pm 21 \mathrm{~m} \mathrm{~s}^{-1}$ in East Asia, respectively. The results also indicated that the amplitudes of LSTIDs decreased during their propagation for every event, and the daytime damping rates were more than 1 time larger than the nighttime ones due to different ion drag between daytime and nighttime. The source regions of the LSTIDs were likely to be located between geomagnetic latitudes of $68^{\circ} \mathrm{N}$ and $62^{\circ} \mathrm{N}$ in North America, and between $65^{\circ} \mathrm{N}$ and $57^{\circ} \mathrm{N}$ in Europe, according to the variation of magnetic $\mathrm{H}$ component observed in these two regions.
\end{abstract}

Keywords. Ionosphere (Ionospheric disturbances; Ionospheric irregularities; Particle precipitation)

\section{Introduction}

Large-scale traveling ionospheric disturbances (LSTIDs) are the response of the ionosphere to atmospheric gravity waves (AGWs), launched by high latitudes sources such as Joule heating, Lorentz forces, or intense particle precipitations (Hunsucker, 1982). The gravity waves interact with the ionosphere and thus cause equatorward propagating LSTIDs. The LSTIDs have a horizontal scale of more than $1000 \mathrm{~km}$ and propagate equatorward at a velocity of $400 \sim 1000 \mathrm{~m} \mathrm{~s}^{-1}$ (e.g. Hunsucker, 1982; Hocke and Schlegel, 1996).

Since the investigation on LSTIDs provides important information about energy and momentum transportation from high latitudes to low latitudes in the ionosphere, the observation of LSTIDs in the auroral region and their propagation from high to low latitudes have been widely studied by many authors. Early studies were mainly based on the sparse distributional equipments, such as ionosondes, HF Doppler sounding, satellite beacons, and incoherent scatter radars. One of these early observations was operated by Hajkowicz (1991), who used data from a large network of 46 ionosonde stations operating throughout the Earth to observe the global propagation of LSTIDs during great substorms of 13 March 1989. Rice et al. (1988) utilized the combined observation of incoherent scatter radars, ionosondes, HF radars and optical measurements, to investigate the global propagation of LSTIDs at midlatitudes. Both of the observations of Hajkowicz (1991) and Rice et al. (1988) showed a consecutive fluctuation of F2-layer virtual height and corresponding critical frequency from high to low latitudes, indicating the presence of LSTIDs. 
Table 1. Locations and Codes of GPS receivers used in this paper.

\begin{tabular}{|c|c|c|}
\hline GPS receiver & Geographical location & Geomagnetic location \\
\hline WSLR & $50.1^{\circ} \mathrm{N}, 122.9^{\circ} \mathrm{W}$ & $55.3^{\circ} \mathrm{N}, 63.6^{\circ} \mathrm{W}$ \\
\hline NANO & $49.3^{\circ} \mathrm{N}, 124.1^{\circ} \mathrm{W}$ & $54.9^{\circ} \mathrm{N}, 65.4^{\circ} \mathrm{W}$ \\
\hline CHWK & $49.2^{\circ} \mathrm{N}, 122.0^{\circ} \mathrm{W}$ & $54.6^{\circ} \mathrm{N}, 62.3^{\circ} \mathrm{W}$ \\
\hline FTS1 & $46.2^{\circ} \mathrm{N}, 123.9^{\circ} \mathrm{W}$ & $52.0^{\circ} \mathrm{N}, 63.4^{\circ} \mathrm{W}$ \\
\hline KELS & $46.1^{\circ} \mathrm{N}, 122.9^{\circ} \mathrm{W}$ & $52.1^{\circ} \mathrm{N}, 67.6^{\circ} \mathrm{W}$ \\
\hline $\mathrm{CHZZ}$ & $45.5^{\circ} \mathrm{N}, 124.0^{\circ} \mathrm{W}$ & $51.3^{\circ} \mathrm{N}, 63.3^{\circ} \mathrm{W}$ \\
\hline DDSN & $43.1^{\circ} \mathrm{N}, 123.2^{\circ} \mathrm{W}$ & $49.1^{\circ} \mathrm{N}, 61.2^{\circ} \mathrm{W}$ \\
\hline CABL & $42.8^{\circ} \mathrm{N}, 124.6^{\circ} \mathrm{W}$ & $48.6^{\circ} \mathrm{N}, 63.4^{\circ} \mathrm{W}$ \\
\hline PSTG & $41.8^{\circ} \mathrm{N}, 124.3^{\circ} \mathrm{W}$ & $47.7^{\circ} \mathrm{N}, 62.5^{\circ} \mathrm{W}$ \\
\hline YBHB & $41.7^{\circ} \mathrm{N}, 122.7^{\circ} \mathrm{W}$ & $47.8^{\circ} \mathrm{N}, 59.8^{\circ} \mathrm{W}$ \\
\hline TRND & $41.1^{\circ} \mathrm{N}, 124.2^{\circ} \mathrm{W}$ & $47.0^{\circ} \mathrm{N}, 62.1^{\circ} \mathrm{W}$ \\
\hline РОТВ & $38.2^{\circ} \mathrm{N}, 121.9^{\circ} \mathrm{W}$ & $43.5^{\circ} \mathrm{N}, 58.9^{\circ} \mathrm{W}$ \\
\hline OXMT & $37.5^{\circ} \mathrm{N}, 122.4^{\circ} \mathrm{W}$ & $42.7^{\circ} \mathrm{N}, 59.2^{\circ} \mathrm{W}$ \\
\hline ANA1 & $34.0^{\circ} \mathrm{N}, 119.4^{\circ} \mathrm{W}$ & $39.8^{\circ} \mathrm{N}, 55.1^{\circ} \mathrm{W}$ \\
\hline GUAX & $28.9^{\circ} \mathrm{N}, 118.3^{\circ} \mathrm{W}$ & $34.8^{\circ} \mathrm{N}, 52.8^{\circ} \mathrm{W}$ \\
\hline POTS & $52.4^{\circ} \mathrm{N}, 14.0^{\circ} \mathrm{E}$ & $52.0^{\circ} \mathrm{N}, 99.0^{\circ} \mathrm{E}$ \\
\hline PTBB & $52.3^{\circ} \mathrm{N}, 10.5^{\circ} \mathrm{E}$ & $52.6^{\circ} \mathrm{N}, 95.8^{\circ} \mathrm{E}$ \\
\hline JOZE & $52.1^{\circ} \mathrm{N}, 21.0^{\circ} \mathrm{E}$ & $47.7^{\circ} \mathrm{N}, 96.8^{\circ} \mathrm{E}$ \\
\hline DRES & $51.0^{\circ} \mathrm{N}, 15.0^{\circ} \mathrm{E}$ & $50.5^{\circ} \mathrm{N}, 99.5^{\circ} \mathrm{E}$ \\
\hline UZHL & $48.6^{\circ} \mathrm{N}, 20.3^{\circ} \mathrm{E}$ & $47.2^{\circ} \mathrm{N}, 103.4^{\circ} \mathrm{E}$ \\
\hline OBE2 & $48.1^{\circ} \mathrm{N}, 11.3^{\circ} \mathrm{E}$ & $48.4^{\circ} \mathrm{N}, 94.6^{\circ} \mathrm{E}$ \\
\hline HFLK & $47.3^{\circ} \mathrm{N}, 11.4^{\circ} \mathrm{E}$ & $47.6^{\circ} \mathrm{N}, 94.4^{\circ} \mathrm{E}$ \\
\hline ZIMM & $46.9^{\circ} \mathrm{N}, 7.5^{\circ} \mathrm{E}$ & $47.9^{\circ} \mathrm{N}, 90.4^{\circ} \mathrm{E}$ \\
\hline NOVA & $45.4^{\circ} \mathrm{N}, 8.6^{\circ} \mathrm{E}$ & $46.3^{\circ} \mathrm{N}, 90.9^{\circ} \mathrm{E}$ \\
\hline TORI & $45.1^{\circ} \mathrm{N}, 7.7^{\circ} \mathrm{E}$ & $46.2^{\circ} \mathrm{N}, 89.9^{\circ} \mathrm{E}$ \\
\hline GENO & $44.4^{\circ} \mathrm{N}, 8.9^{\circ} \mathrm{E}$ & $45.3^{\circ} \mathrm{N}, 90.8^{\circ} \mathrm{E}$ \\
\hline PENC & $47.8^{\circ} \mathrm{N}, 19.3^{\circ} \mathrm{E}$ & $46.6^{\circ} \mathrm{N}, 102.1^{\circ} \mathrm{E}$ \\
\hline BUCU & $44.5^{\circ} \mathrm{N}, 26.1^{\circ} \mathrm{E}$ & $39.3^{\circ} \mathrm{N}, 99.9^{\circ} \mathrm{E}$ \\
\hline ORID & $41.1^{\circ} \mathrm{N}, 20.8^{\circ} \mathrm{E}$ & $35.3^{\circ} \mathrm{N}, 94.7^{\circ} \mathrm{E}$ \\
\hline NOT1 & $36.9^{\circ} \mathrm{N}, 15^{\circ} \mathrm{E}$ & $30.4^{\circ} \mathrm{N}, 89.1^{\circ} \mathrm{E}$ \\
\hline HLAR & $49.3^{\circ} \mathrm{N}, 119.7^{\circ} \mathrm{E}$ & $38.4^{\circ} \mathrm{N}, 188.8^{\circ} \mathrm{E}$ \\
\hline CHUN & $43.8^{\circ} \mathrm{N}, 125.4^{\circ} \mathrm{E}$ & $33.2^{\circ} \mathrm{N}, 192.0^{\circ} \mathrm{E}$ \\
\hline BJSH & $40.3^{\circ} \mathrm{N}, 116.2^{\circ} \mathrm{E}$ & $29.4^{\circ} \mathrm{N}, 186.2^{\circ} \mathrm{E}$ \\
\hline JIXN & $40.1^{\circ} \mathrm{N}, 117.5^{\circ} \mathrm{E}$ & $29.2^{\circ} \mathrm{N}, 187.4^{\circ} \mathrm{E}$ \\
\hline BJFS & $39.6^{\circ} \mathrm{N}, 115.9^{\circ} \mathrm{E}$ & $28.6^{\circ} \mathrm{N}, 185.9^{\circ} \mathrm{E}$ \\
\hline TAIN & $36.2^{\circ} \mathrm{N}, 117.1^{\circ} \mathrm{E}$ & $25.3^{\circ} \mathrm{N}, 187.1^{\circ} \mathrm{E}$ \\
\hline SHAO & $31.1^{\circ} \mathrm{N}, 121.2^{\circ} \mathrm{E}$ & $20.3^{\circ} \mathrm{N}, 190.9^{\circ} \mathrm{E}$ \\
\hline XIAM & $24.4^{\circ} \mathrm{N}, 118.1^{\circ} \mathrm{E}$ & $13.5^{\circ} \mathrm{N}, 188.4^{\circ} \mathrm{E}$ \\
\hline
\end{tabular}

Since 1990s, the development of the global positioning system (GPS) and the creation (on its basis) of the network IGS (International GNSS Service), which included more than 1000 GPS receivers (since 2004) all around the world, opened a new era in the remote exploration of the ionosphere. With its advantages of simultaneous global coverage, high resolution in time, continuous measurements and data availability, we can monitor the LSTIDs continuously in a wide range. Many LSTIDs have been observed in the regions with dense distribution of GPS receivers, including North America (Afraimovich et al., 2000; Ding et al., 2007, 2008) and Japan (Saito et al., 2001; Shiokawa et al., 2002; Tsugawa et al., 2004). Afraimovich et al. (2000) used the GPS arrays in North America to investigate the form and dynamics of LSTIDs during a strong magnetic storm of 25 September 1998. They found that the LSTIDs curled to the west in longitude where the local time was around afternoon. Ding et al. (2008) used a 3-year period (2003 2005) data observed by more than 600 GPS receivers in North America to study the characteristics of LSTIDs. They found that the occurrence of LSTIDs was dependent on local time. Saito et al. (2001) used a cluster of all-sky CCD cameras and a GPS network operated by the GEONET to clarify the characteristics of nighttime TID in FRONT campaign carried out in May 1998 and August 1999 in Japan. They found that the propagation direction of TID was restricted to the southwest and the TID structure intensified as it traveled to low latitudes. Shiokawa et al. (2002) investigated a prominent LSTID in Japan on 15 September 1999 using both 630$\mathrm{nm}$ airglow images and GPS data from the GPS Earth observation network (GEONET), they found that the LSTID moved equatorward over Japan with a velocity of about $400 \sim 450 \mathrm{~m} \mathrm{~s}^{-1}$. Tsugawa et al. (2004) statistically studied the LSTIDs in Japan from April 1999 to December 2002 using GPS TEC data from GEONET, they found that the occurrence rate of the disturbed-time LSTIDs was positively correlated with $\mathrm{Kp}$ value, and the amplitude damping and growth of the LSTIDs were mainly caused by the upward and downward propagating AGW through ion-drag effect, respectively.

The papers cited above had revealed various features of the regional LSTIDs structures and propagation characteristics. Analysis of the global propagation features of LSTIDs has not frequently been seen in recent years. Hajkowicz (1990) used the data from ionosonde stations operating throughout the Earth at the time of disturbance to investigate the conjugate effects of LSTIDs in Japan and Australia. They found that the storm-induced height rises were only pronounced in the night time sectors. Tsugawa et al. (2003) derived the damping rates of LSTIDs between different latitudes in several local time sectors during the geomagnetic storm on 22 September 1999. They indicated that the damping of LSTIDs was mainly caused by the ion-drag effect. Tsugawa et al. (2006) used the GPS TEC data from GPS networks in Japan and Australia to study the geomagnetic conjugacy of LSTIDs; they found that the almost simultaneous LSTIDs in both hemispheres were not connected electromagnetically through the geomagnetic field, and the asymmetry of LSTID in two hemispheres might be caused by asymmetry of the energy input in the auroral zone. Some specific characteristics of LSTIDs such as the variations of the LSTIDs' propagation azimuths with latitudes and the difference of the LSTIDs' horizontal phase velocities between different regions have not received enough attention.

The aim of this paper is to investigate some detailed information of LSTIDs identified in the sectors of North America, Europe, and East Asia during the magnetic storm of 7 10 November 2004. The results revealed several new characteristics of the LSTIDs, such as the latitudinal 


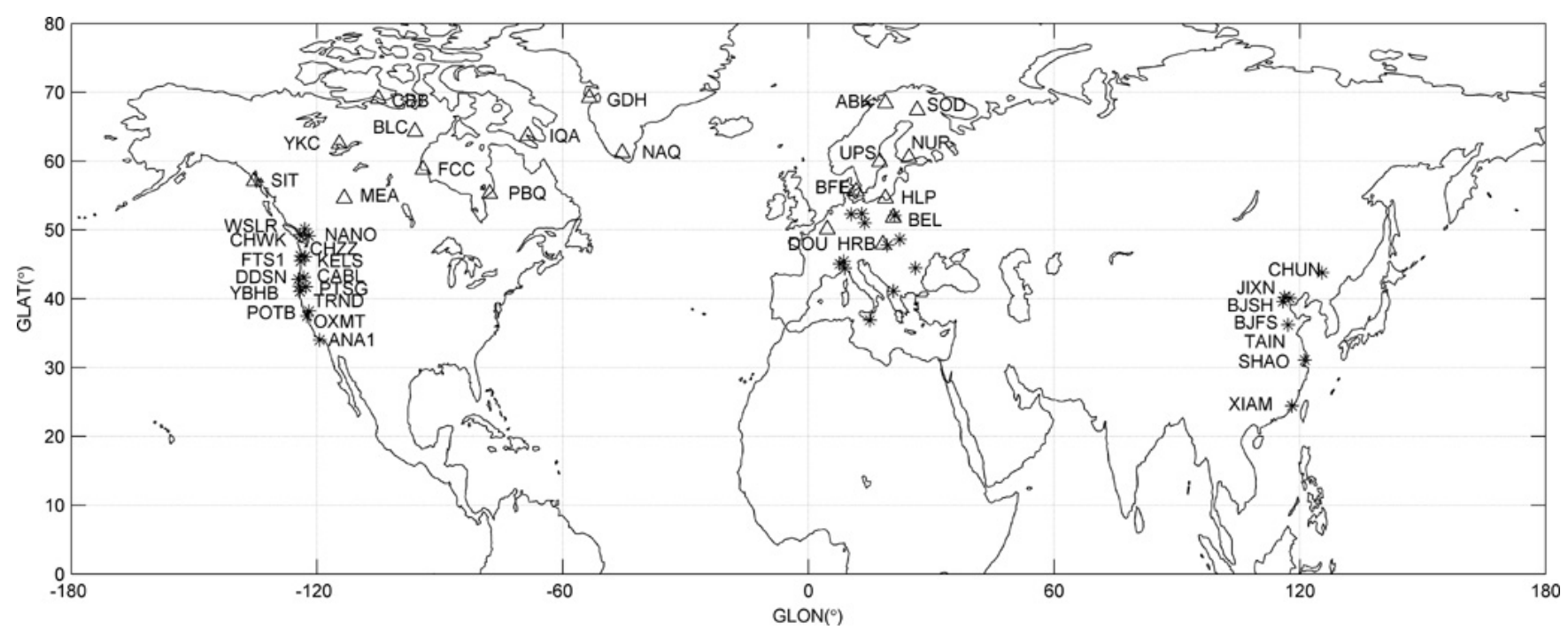

Fig. 1. Geodetic locations of geomagnetic observatories (triangle) and locations of the GPS receivers (asterisk) used in this paper. The code name for each geomagnetic observatory was marked on the map, and the names of some GPS receivers were also marked on the map.

dependence of the LSTIDs' propagation azimuths and the different mean horizontal phase velocities of LSTIDs among different sectors.

\section{Data and method}

\subsection{Data and selection of GPS stations}

The GPS TEC data used in this study were provided by the Scripps Orbit and Permanent Array Center (SOPAC) and IGS. We got the data observed from dual-frequency GPS receivers, which were more than 1000 all around the world in 2004. Each GPS receiver generated RINEX files recording carrier phase delays and group delays. We retrieved the original slant TEC time series from the RINEX files and removed the outliers and wild points.

We chose the longitudinally extended chain stations in North America, Europe, and East Asia to observe northsouth motion of LSTIDs. In order to get more information of the LSTIDs during 7 10 November 2004, we chose the GPS arrays in these three sectors and applied the multichannel maximum-entropy method to get the propagation parameters of LSTIDs, including horizontal phase velocity and propagation azimuth. We selected 3 sets of GPS arrays longitudinally located at different geomagnetic latitudes of $55.3^{\circ} \mathrm{N}, 51.3^{\circ} \mathrm{N}$, and $47.7^{\circ} \mathrm{N}$ in North America, and of $52.6^{\circ} \mathrm{N}, 47.6^{\circ} \mathrm{N}$, and $45.3^{\circ} \mathrm{N}$ in Europe, respectively. We found only 1 set of GPS array located at geomagnetic latitude of $28.6^{\circ} \mathrm{N}$ in East Asia. Each of these GPS arrays consisted of three GPS receivers, and the horizontal distance among these receivers of each array was less than the half of the horizontal wavelength of the LSTID to avoid phase integer cycle ambiguity. The geographical and geomagnetic latitudes and longitudes of all the 38 GPS sites and their codes used in this paper are listed in Table 1, and the geodetic locations of these GPS receivers are plotted as asterisks in Fig. 1.

\subsection{Multichannel maximum-entropy method}

We applied the multichannel maximum-entropy method to the GPS arrays chosen above to calculate the parameters of LSTIDs. First, we calculated the original slant TEC time series along the receiver-satellite lines of sight from the data of dual-frequency carrier phase and pseudo-range measurements of GPS receivers. Then we converted the slant TEC time series into vertical TEC (VTEC) time series by equation

$\mathrm{VTEC}=\left(\mathrm{STEC}+B_{\mathrm{r}}^{\mathrm{s}}\right)$ sinele

where "ele" was the satellite elevation angle, STEC was the real measurement of slant TEC, VTEC was the vertical TEC time series, and $B_{\mathrm{r}}^{\mathrm{s}}$ was the instrumental receiver and satellite biases. We used the data with satellite elevation larger than $30^{\circ}$ to minimize the errors caused by converting slant TEC into vertical TEC and the multipath effects. $B_{\mathrm{r}}^{\mathrm{s}}$ was the main error source of the ionospheric TEC deriving from GPS observation and could reach up to several TECU $\left(1 \mathrm{TECU}=10^{16}\right.$ electrons $\left.\mathrm{m}^{-2}\right)$ or even larger than the real slant TEC (Sardón and Zarraoa, 1997; Zhang et al., 2010), and the effect of this biases must be removed to get the absolute measurements of TEC. Here, we eliminated the $B_{\mathrm{r}}^{\mathrm{s}}$ by combining the vertical TEC time series (VTEC) with the JPL GIM data which was interpolated in both space and time.

Second, we got the background trend of vertical TEC $\left(\mathrm{TEC}_{0}\right.$ ) by smoothing the vertical TEC time series (VTEC) with the chosen sliding window of $120 \mathrm{~min}$ (Ding et al., 
2004). It was necessary to notice that medium-scale TID (MSTID), which had wavelengths of several hundred kilometers, often overlapped the LSTID structure and made distortion of LSTID wavefront (Tsugawa et al., 2007). The possible occurrence of MSTIDs may distort the TID series and consequently cause errors during the estimation of LSTID parameters (Tsugawa et al., 2003, 2004). The period of MSTIDs in winter was less than 30 min (Kotake et al., 2007), in order to reduce the errors due to MSTIDs overlapping the LSTID, we smoothed the VTEC with a selected time window of $30 \mathrm{~min}$ and removed the background trend of vertical TEC $\left(\mathrm{TEC}_{0}\right)$. Thus we derived the time series of the deviation of TEC (DTEC) in the period range 30-120 min corresponding to the LSTID periods. In the end, by adopting the three-channel maximum entropy method (Strand, 1977), we derived the main frequency and phase differences between DTEC time series observed at three GPS stations (a GPS array) to determine the propagation parameters. Galileo transformation was applied to eliminate the error caused by the Doppler shift in the DTEC time series due to the movements of GPS satellites (Wan et al., 1997).

Two criteria were required during the identification of a LSTID event. (1) The maximum amplitudes of wave-like variation in DTEC time series should exceed 0.5 TECU. This criterion was based on the previous researches, Tsugawa et al. (2006) defined the LSTIDs as the TEC enhancements larger than 0.5 TECU; Ding et al. (2008) found the amplitudes of TEC variation caused by LSTIDs were mostly around 1.1 TECU. (2) The temporal variation of wave period, azimuth, and horizontal phase velocity obtained from multichannel maximum-entropy method should not change too much. The second criterion was set to ensure that we observed a steady wave field and that the parameters thus obtained were reliable.

\subsection{Generation of two-dimensional TEC perturbation maps}

For the sectors with the GPS receivers distributed much denser than East Asia, such as North America, we combined the multichannel maximum-entropy method and the TEC mapping method, the later one can visually illustrate the two dimension distribution of the LSTIDs' wavefronts.

The method of creating two-dimensional TEC perturbation maps was introduced in detail by Ding et al. (2007) which was similar to that of Tsugawa et al. (2003) and Nicolls et al. (2004). First, we obtained the vertical TEC time series (VTEC) from the original slant TEC time series by Eq. (1).

Second, we expanded the background trends of vertical TEC $\left(\right.$ VTEC $\left._{0}\right)$ as

$\mathrm{VTEC}_{0}=C_{0}+C_{1}\left(\mathrm{lat}-\mathrm{lat}_{0}\right)+C_{2}\left(\mathrm{LT}-\mathrm{LT}_{0}\right)$

here lat and LT were the geographical latitude and local time, respectively. $C_{0}, C_{1}$, and $C_{2}$ were the fitting coefficients. $\mathrm{LT}_{0}$ was the local time when the satellite elevation angle "ele" reached the maximum and lat $_{0}$ was the latitude of the ionospheric pierce point at time $\mathrm{LT}_{0}$.

Third, we obtained the deviation of vertical TEC time series by subtracting the $\mathrm{VTEC}_{0}$ from the VTEC and applied this filtering method to the densely distributed GPS receivers of North America to get the two-dimensional TEC perturbation maps with the spatial resolution of $0.5^{\circ}$ latitude $\times 0.5^{\circ}$ longitude and temporal resolution of $150 \mathrm{~s}$. Then, we checked the TEC variation maps to see if there were regularly moving band-like structures representing the existence of LSTIDs.

\section{Statistical results}

\subsection{Geomagnetic condition}

Figure 2 plotted the temporal variations of SYM-H (a), AU and $\mathrm{AL}$ (b) indices during 7 10 November 2004. During this period, two major magnetic storms occurred. The first storm began its main phase at about 20:00 UT on the 7 th, then the SYM-H index reached its first minimum of $-373 \mathrm{nT}$ at approximately 06:00 UT on the 8th. During the recovery phase of the first storm, a second storm occurred between roughly 21:00 UT on the 9th and 23:00 UT on the 10th, with the value of SYM-H reached a second minimum of $-300 \mathrm{nT}$ on the 10th. During this period, several intense auroral substorms happened as shown by the enhancements of AU and AL indices on panel (b), where the peak value of AL values exceeding $4000 \mathrm{nT}$.

During this period, 11 LSTID events were identified, which propagated at global scale and can be observed by GPS network at the sectors of North America, Europe, and East Asia.

\subsection{LSTID events on 7 November}

Two LSTID events were observed almost simultaneously between 20:00 22:30 UT. In North America, it was at 13:00 14:30 LT (21:00 22:30 UT), and in Europe, it was at 21:00 22:25 LT (20:00 21:25 UT). Figure 3a, e plotted the temporal dependence of the deviation of TEC (DTEC) observed at certain GPS stations between 08:00 16:00 LT (16:00 24:00 UT) along the meridian of $120^{\circ} \mathrm{W}$ in North America and between 17:00 23:00 LT (16:00 22:00 UT) along the meridian of $20^{\circ} \mathrm{E}$ in Europe, respectively. Strong oscillation in DTEC series was observed in North America during this time (Fig. 3a), the oscillation traveled to the distance of $\sim 2000 \mathrm{~km}$. Almost at the same time period, a LSTID event was identified in Europe as shown in Fig. 3e. The dissipation of the amplitudes of the LSTIDs during their propagation from high to low latitudes were different between these two sectors when comparing the damping rates of these two LSTIDs. The damping rate hereafter was defined as the exponential decreased rate of the ratio of the 


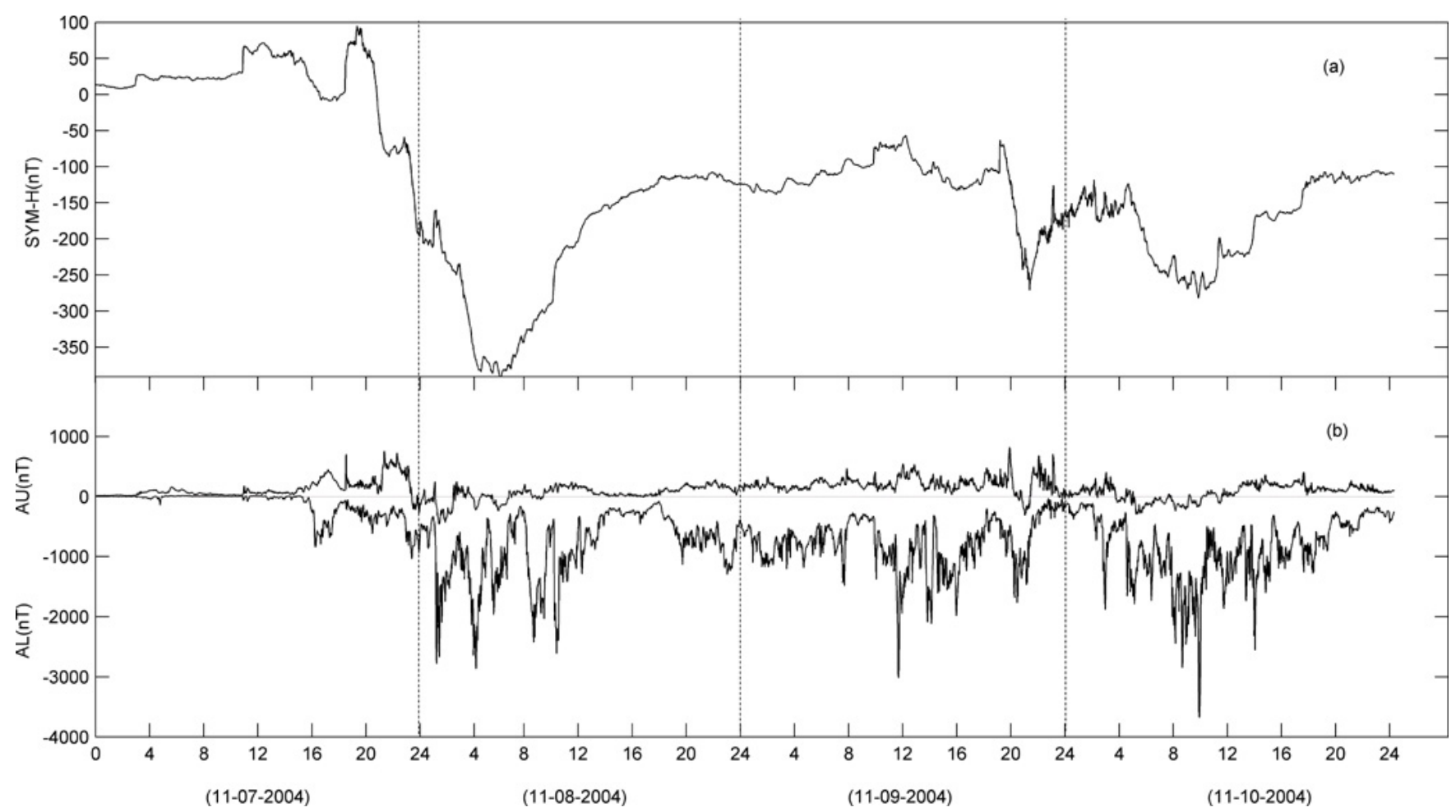

Fig. 2. The variations of the SYM-H (a), AU and AL (b) indices on 7 10 November 2004.

perturbation component of TEC (DTEC) to the vertical background component $\left(\mathrm{TEC}_{0}\right)$ (Tsugawa et al., 2003). The amplitude attenuated rate was $0.011 / 100 \mathrm{~km}$ in Europe in the evening, while it was $0.031 / 100 \mathrm{~km}$ in North America around noon time.

The occurred time of the maximum AU index corresponded with the time when the LSTID events were observed in both North America and Europe, this was good evidence that the occurrence of LSTIDs was highly correlated with the enhancements of auroral electrojets during magnetic storms. It was noteworthy that we did not find any LSTID event in Asia on this day; this may be because most of the GPS stations in East Asia are located in low latitude regions.

\subsection{LSTID events on 8 November}

On 8 November 2004, a series of auroral substorms happened during 01:00 12:00 UT that were indicated by the enormous drop of the AL index with its minimum reaching $-3000 \mathrm{nT}$ around 04:00 UT (Fig. 2b). The intensive occurrences of the auroral substorms during this time made it difficult to identify LSTID events from the complex variation of TEC. However, we still observed one LSTID event between 02:00 and 03:30 UT in North America (Fig. 3b) and one LSTID event between 03:12 and 05:00 UT in Europe (Fig. 3f), as well as one LSTID event between 10:00 and 11:36 UT in East Asia (Fig. 3i), respectively.
In North America, we observed a LSTID propagating to the distance of more than $1200 \mathrm{~km}$ with the maximum amplitude of $\sim 2$ TECU at 18:00 19:30 LT (02:00 03:30 UT), as shown in Fig. 3b. At 04:12 06:00 LT (03:12 05:00 UT) we observed a LSTID in Europe with the maximum amplitude of $\sim 1 \mathrm{TECU}$, it propagated to the distance of more than $1500 \mathrm{~km}$ (Fig. 3f). In Asia we also observed a LSTID propagating to the distance of more than $1500 \mathrm{~km}$ at 18:00 19:36 LT (10:00 11:36 UT), its maximum amplitude was about 2 TECU, as shown in Fig. 3i. The damping rates of the LSTIDs in North America, Europe and East Asia were $0.014 / 100 \mathrm{~km}, 0.013 / 100 \mathrm{~km}$, and $0.028 / 100 \mathrm{~km}$, respectively.

Depending on the intensively distributed GPS sites in North America, we got the time sequence of twodimensional maps of TEC perturbations over North America on 7 10 November 2004 during the passage of LSTIDs. Spatial resolution for the TEC maps was $0.5^{\circ}$ latitude $\times 0.5^{\circ}$ longitude and temporal resolution was $150 \mathrm{~s}$. In this paper, the maps during the period between 02:00 and 04:00 UT on 8 November 2004 were shown to see the movement of the phase fronts of LSTID (Fig. 4a e). As shown in Fig. 4a, a positive TEC perturbation bands first occurred in the northwest of United States at around $50^{\circ} \mathrm{N}$ at 02:00 UT, and a strong negative band appeared at the same time at latitude of $40^{\circ} \mathrm{N}$. A phase front can be clearly seen, which was the border between the positive and the negative region. Around 02:30 UT the positive band at $50^{\circ} \mathrm{N}$ moved to the latitude 


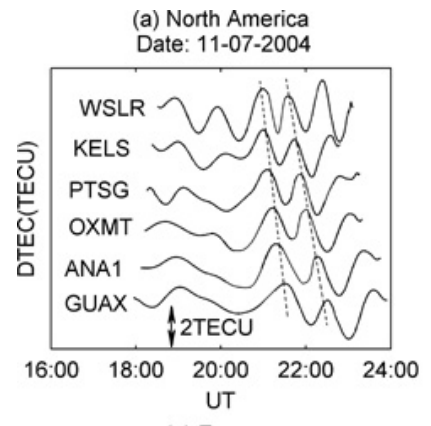

(e) Europe

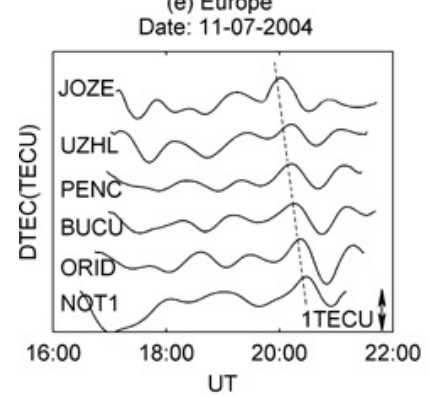

(i) East Asia

Date: 11-08-2004

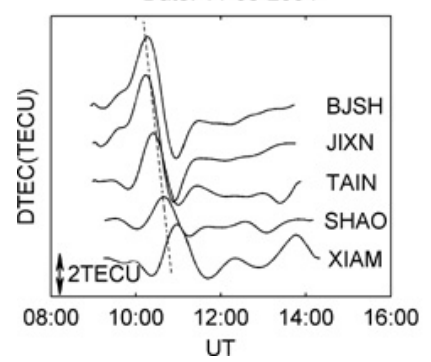

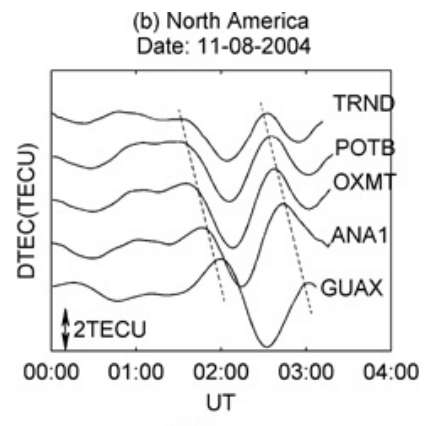

(f) Europe
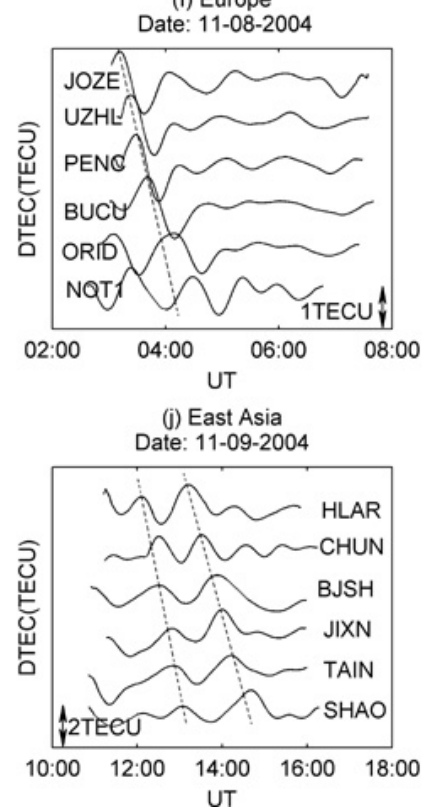
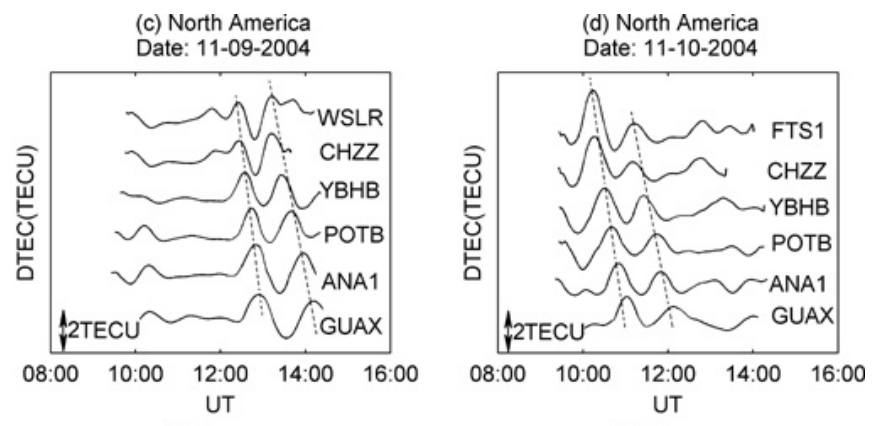

(g) Europe
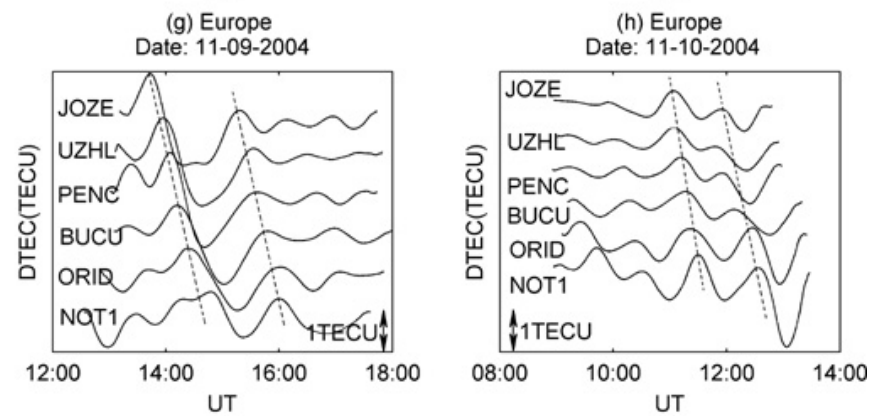

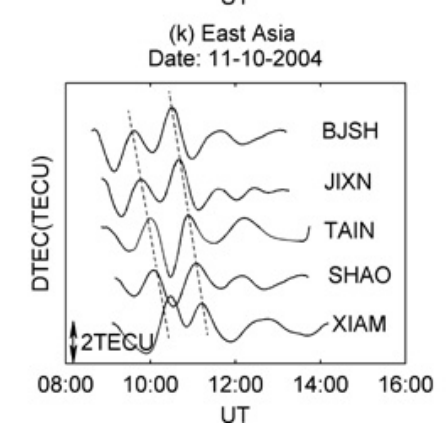

Fig. 3. The time dependence of the deviations of TEC (DTEC) in North America (a) $\sim(\mathbf{d})$ and in Europe (e) $\sim(\mathbf{h})$ on $7 \sim 10$ November 2004 and in East Asia (i) $\sim(\mathbf{k})$ on $8 \sim 10$ November 2004 for TEC data from GPS receivers along longitude of about $120^{\circ} \mathrm{W}(\mathbf{a}) \sim(\mathbf{d}), 20^{\circ} \mathrm{E}(\mathbf{e}) \sim(\mathbf{h})$ and $120^{\circ} \mathrm{E}(\mathbf{i}) \sim(\mathbf{k})$, respectively. The names of the GPS receivers were marked in each of the picture. The phase fronts of the LSTIDs were marked with dash lines.

of $\sim 40^{\circ} \mathrm{N}$, and the negative band at $40^{\circ} \mathrm{N}$ moved to the latitude of $30^{\circ} \mathrm{N}$; meanwhile a negative appeared at the latitude of $\sim 50^{\circ} \mathrm{N}$. Then these bands continuously moved to lower latitude between 03:00 03:30 UT (Fig. 4c $\sim$ d). The phase fronts passed over the United States with the duration of about one and a half hours. The perturbation structures gradually disappeared in the maps after 04:00 UT (Fig. 4e).

\subsection{LSTID events on 9 November}

Several substorms occurred during the recovery phase of the first magnetic storm on 9 November. The strongest substorm occurred at 12:00 UT with the value of AL dropping to $3000 \mathrm{nT}$, which far exceeded the drop of AL index of other substorms during that day. Consequently, obvious LSTID events were observed after 12:00 UT, right after the expansion phase of the strongest substorm.

As shown in the Fig. 3c, a LSTID event was found at 04:20 06:00 LT (12:20 14:00 UT) at middle latitudes of North America propagating to the distance of almost $2000 \mathrm{~km}$; with the maximum amplitude of 2 TECU. We also found a LSTID at high and middle latitudes of Europe at 15:00 17:00 LT (14:00 16:00 UT) and a LSTID at middle and low latitudes of East Asia at 20:00 23:00 LT $(12: 00 \sim 15: 00 \mathrm{UT})$ as shown in Fig. $3 \mathrm{~g}$ and $3 \mathrm{j}$, respectively. The maximum amplitudes in Europe and Asia were 1.5 TECU and $2 \mathrm{TECU}$, respectively. The damping rate of the LSTIDs in North America, Europe, and East Asia were $0.016 / 100 \mathrm{~km}, 0.03 / 100 \mathrm{~km}$, and $0.018 / 100 \mathrm{~km}$, respectively.

\subsection{LSTID events on 10 November}

On 10 November the AL index reached its minimum of almost 4000 nT around 10:00 UT, accordingly we found one LSTID event in each sector around 10:00 UT as plotted in Fig. 3d, h, k. We observed the LSTID propagating to the distance of $2000 \mathrm{~km}$ with the maximum amplitude of about 2 TECU at 02:00 04:00 LT (10:00 12:00 UT) in North 

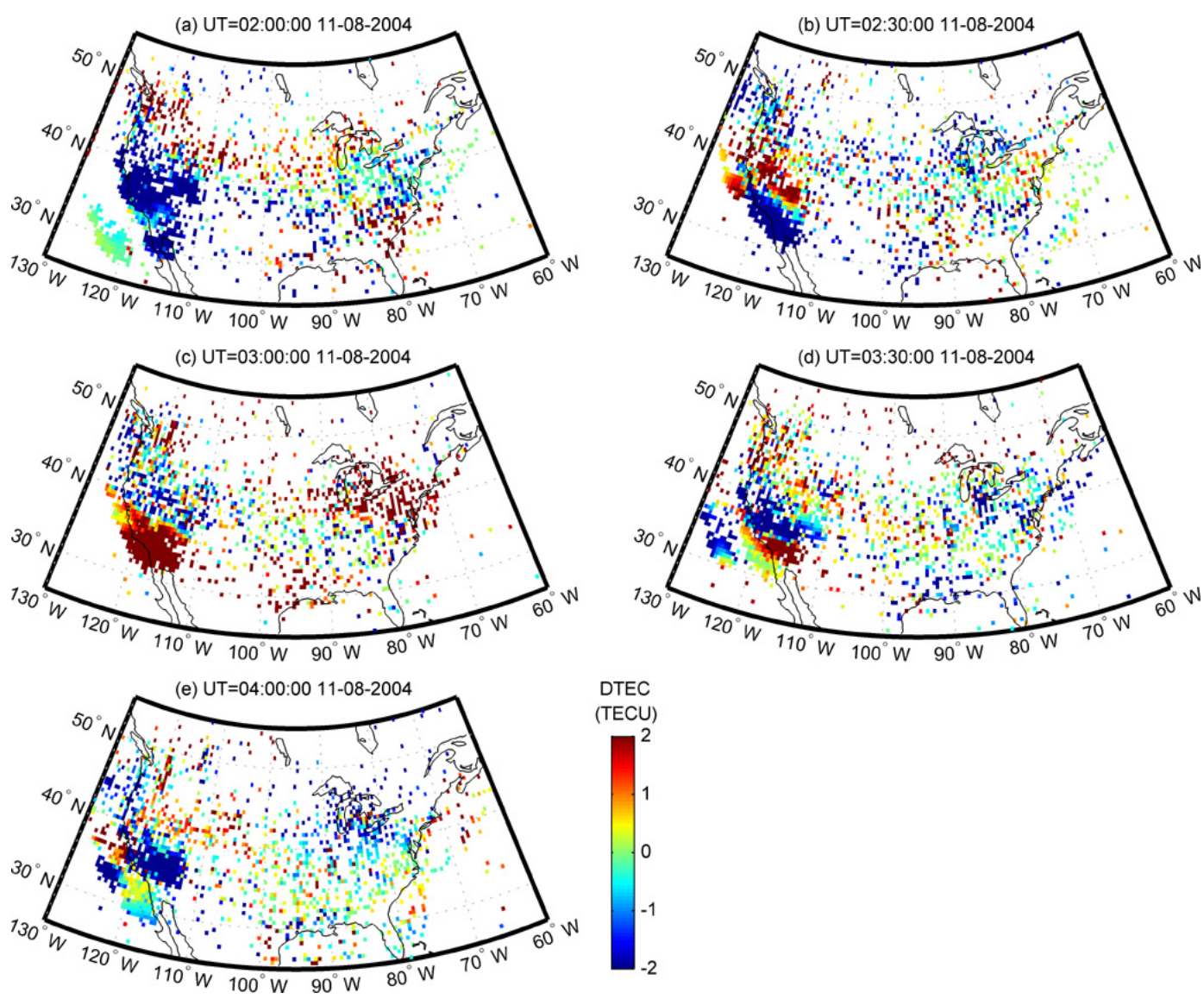

Fig. 4. Time sequence of two-dimensional maps of TEC perturbations over North America during the period of 02:00 04:00 UT on 8 November 2004.

America (Fig. 3d). In Europe, the LSTID propagated to the distance of $1500 \mathrm{~km}$ at 12:00 14:00 LT (11:00 13:00 UT); its maximum amplitude was about 0.75 TECU (Fig. 3h). In East Asia, the LSTID propagated to the distance of about $1600 \mathrm{~km}$ (Fig. 3k) at 18:00 20:00 LT (10:00 12:00 UT), and its maximum amplitude was 2 TECU. The damping rates of the LSTIDs in North America, Europe, and East Asia were $0.025 / 100 \mathrm{~km}, 0.021 / 100 \mathrm{~km}$, and $0.019 / 100 \mathrm{~km}$, respectively.

The time intervals of the LSTID events observed in these three sectors were characterized by the largest value of the $\mathrm{AL}$, which again confirmed that the generation of the LSTIDs was closely associated with the auroral activities.

\section{Discussions}

We have used the GPS TEC data to study the propagation characteristics of the large-scale traveling ionospheric disturbances (LSTIDs) over North America, Europe, and East Asia during the magnetic storm on 7 10 November 2004. 11 LSTIDs were identified, 4 in North America, 4 in Europe, and 3 in East Asia, respectively. The occurrence of the LSTIDs at high latitudes was temporally well-correlated with the occurrence of auroral substorms. But LSTIDs were seldom observed during the time when several strong substorms occurred successively. For example, on 10 November, we found only one LSTID event at each of the three sectors as illustrated in Fig. 3d, h, k, though numbers of substorms occurred during that day. This may be because ionospheric storms occurring during dense substorms tremendously changed the background ionosphere. Consequently, the traces of LSTIDs in TEC series were lost due to strong variation of the background TEC. Interactions among the LSTIDs stimulated by different substorms may be another cause, making it hard to distinguish the phase variation of one LSTID from another in TEC series.

\subsection{Propagation directions of LSTIDs}

By applying the multichannel maximum-entropy method to the deviations of the TEC series at the GPS arrays mentioned in Sect. 2.1, we got the variations of the propagation azimuths of the LSTIDs between geomagnetic latitude of $55.3^{\circ} \mathrm{N}$ and $47.7^{\circ} \mathrm{N}$ in North America, and between geomagnetic latitude of $52.6^{\circ} \mathrm{N}$ and $45.3^{\circ} \mathrm{N}$ in Europe, respectively. 


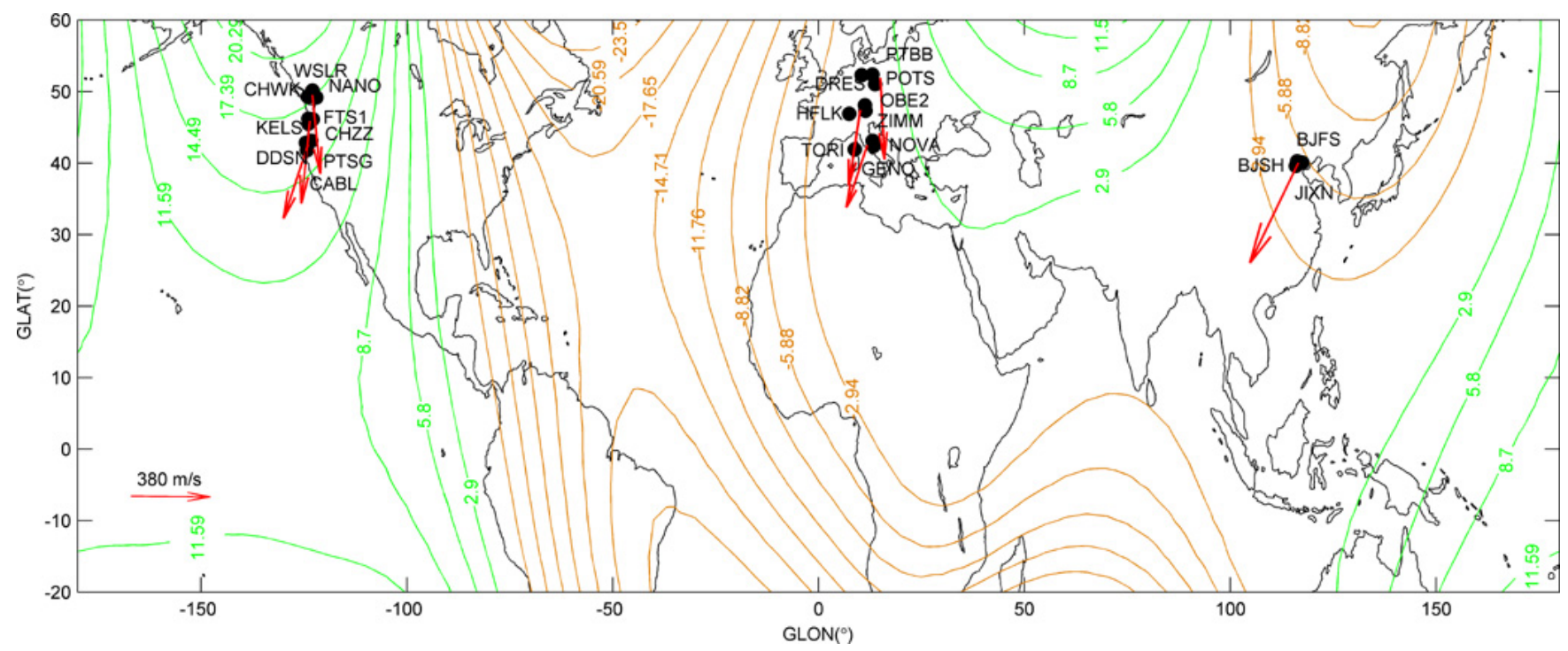

Fig. 5. Propagation parameters of LSTIDs on 9 November 2004. The horizontal phase velocity of LSTID was represented by the length of the red arrow, and the propagation azimuth of LSTID was indicated by arrow's direction. The dots showed the chosen locations of 7arrays, and eastward (westward) declination of the geomagnetic field was presented by the green (brown) contour line.

The results showed that the azimuths of LSTIDs depended on latitudes both in North America and Europe. The azimuth of each LSTID was larger at middle geomagnetic latitude than it was at high geomagnetic latitude, as shown in Table 2. The directions of red arrows in Fig. 5 showed the azimuths of LSTIDs derived from 3 GPS arrays longitudinally distributed at different geomagnetic latitudes in both North America and Europe on 9 November, respectively. The azimuth of LSTID detected in East Asia was also plotted in Fig. 5. As can be seen from Fig. 5, the azimuths of LSTIDs deviated more from south to west as the LSTIDs propagated from high to middle geomagnetic latitudes in both North America and Europe. Since we only got 1 GPS array in East Asia, we cannot tell the propagation azimuth variations of the LSTIDs in this sector, but we still got the averaged westward deviation of about $20^{\circ}$ from south at geomagnetic latitude of $28.6^{\circ} \mathrm{N}$.

Many previous papers have reported the azimuthal directions of the LSTIDs' propagation were not always equatorial but have a clockwise deviation of $\sim 20^{\circ}$ from south (e.g. Afraimovich et al., 2004, 2005; Afraimovich and Voeykov, 2004; Leonovich et al., 2004; Tsugawa et al., 2004; Ding et al., 2008). Tsugawa et al. (2004) statistically studied the LSTIDs in Japan and found the average of the directions of the observed LSTIDs was $3 \pm 19^{\circ}$ east from south, which was thought to be affected by the westward declination of the geomagnetic field in Japan, since the plasma motion is coupled to the geomagnetic field line. The declination of the geomagnetic field is about $-6^{\circ}$ westward from north in Japan, while in North America, the range of the declination of the geomagnetic field varied from $20^{\circ}$ on the west coast to $-23^{\circ}$ on the east coast, which was much larger than that in Japan, as shown in Fig. 5. However, according to the results of this pa- per, the LSTIDs detected in North America had a tendency to southwest, which was in consistent with the statistical study of Ding et al. (2008). This implied that the southwestward LSTIDs in North America would not be mainly affected by the declination of the geomagnetic field.

Figure 5 also showed that the westward deviations from south of the LSTIDs increased as the LSTIDs propagated from high to middle geomagnetic latitudes both in North America and Europe. This implies that the Corilolis force would be one of the main factors of controlling the propagation azimuths of LSTIDs during their propagation. The LSTIDs at high geomagnetic latitudes such as, the GPS array at geomagnetic latitude of $55.3^{\circ} \mathrm{N}$ in North America and the GPS array at geomagnetic latitude of $52.6^{\circ} \mathrm{N}$ in Europe, were near the auroral oval (source region), and were affected by the Coriolis force for a short time, so the southwestward deviations at these arrays were more likely to be related with the generation mechanisms such as the moving source (Hocke and Schlegel, 1996). However, it was obvious that the increased southwestward deviations of the LSTIDs during their propagation from high to middle geomagnetic latitudes were independent of the generation mechanisms which were more likely to be caused by the Coriolis force.

\subsection{Horizontal phase velocities of LSTIDs}

The different lengths of the red arrows plotted in Fig. 5 indicated the different horizontal phase velocities of LSTIDs between different sectors on 9 November 2004. By using the multichannel maximum-entropy method, we got the horizontal phase velocity of LSTIDs in these three sectors during 7 10 November 2004, as shown in Table 2. Statistically, the 
Table 2. Summary of the horizontal phase velocities and propagation azimuths of the 11 LSTIDs events detected from 7 chosen GPS arrays in the three given sectors during the magnetic storm on 7 10 November 2004.

\begin{tabular}{|c|c|c|c|c|c|c|}
\hline Sector & Event & Date & LT & $\begin{array}{c}\text { Geomagnetic latitudes } \\
\text { of GPS arrays }\end{array}$ & $\begin{array}{l}\text { Phase velocity } \\
\qquad\left(\mathrm{m} \mathrm{s}^{-1}\right)\end{array}$ & $\begin{array}{c}\text { Azimuth } \\
\left({ }^{\circ}\right)\end{array}$ \\
\hline \multirow{12}{*}{$\begin{array}{l}\text { North } \\
\text { America }\end{array}$} & \multirow[t]{3}{*}{1} & \multirow[t]{3}{*}{7 th } & \multirow[t]{3}{*}{$13: 00 \sim 14: 30$} & $55.3^{\circ} \mathrm{N}$ & 452 & 185 \\
\hline & & & & $51.3^{\circ} \mathrm{N}$ & 407 & 187 \\
\hline & & & & $47.7^{\circ} \mathrm{N}$ & 426 & 192 \\
\hline & \multirow[t]{3}{*}{2} & \multirow[t]{3}{*}{ 8th } & \multirow[t]{3}{*}{$18: 00 \sim 19: 30$} & $55.3^{\circ} \mathrm{N}$ & 326 & 180 \\
\hline & & & & $51.3^{\circ} \mathrm{N}$ & 428 & 184 \\
\hline & & & & $47.7^{\circ} \mathrm{N}$ & 460 & 189 \\
\hline & \multirow[t]{3}{*}{3} & \multirow[t]{3}{*}{9 th } & \multirow[t]{3}{*}{$04: 20 \sim 06: 00$} & $55.3^{\circ} \mathrm{N}$ & 420 & 180 \\
\hline & & & & $51.3^{\circ} \mathrm{N}$ & 434 & 193 \\
\hline & & & & $47.7^{\circ} \mathrm{N}$ & 457 & 210 \\
\hline & \multirow[t]{3}{*}{4} & \multirow[t]{3}{*}{ 10th } & \multirow[t]{3}{*}{$02: 00 \sim 04: 00$} & $55.3^{\circ} \mathrm{N}$ & 392 & 191 \\
\hline & & & & $51.3^{\circ} \mathrm{N}$ & 448 & 200 \\
\hline & & & & $47.7^{\circ} \mathrm{N}$ & 416 & 207 \\
\hline \multirow{12}{*}{ Europe } & \multirow[t]{3}{*}{5} & \multirow[t]{3}{*}{7 th } & \multirow{3}{*}{$21: 00 \sim 22: 25$} & $52.6^{\circ} \mathrm{N}$ & 307 & 183 \\
\hline & & & & $47.6^{\circ} \mathrm{N}$ & 425 & 191 \\
\hline & & & & $45.3^{\circ} \mathrm{N}$ & 419 & 194 \\
\hline & \multirow[t]{3}{*}{6} & \multirow[t]{3}{*}{ 8th } & \multirow[t]{3}{*}{$04: 12 \sim 06: 00$} & $52.6^{\circ} \mathrm{N}$ & 327 & 190 \\
\hline & & & & $47.6^{\circ} \mathrm{N}$ & 460 & 197 \\
\hline & & & & $45.3^{\circ} \mathrm{N}$ & 471 & 201 \\
\hline & \multirow[t]{3}{*}{7} & \multirow[t]{3}{*}{9 th } & \multirow[t]{3}{*}{$15: 00 \sim 17: 00$} & $52.6^{\circ} \mathrm{N}$ & 440 & 180 \\
\hline & & & & $47.6^{\circ} \mathrm{N}$ & 421 & 196 \\
\hline & & & & $45.3^{\circ} \mathrm{N}$ & 387 & 208 \\
\hline & \multirow[t]{3}{*}{8} & \multirow[t]{3}{*}{ 10th } & \multirow[t]{3}{*}{$12: 00 \sim 14: 00$} & $52.6^{\circ} \mathrm{N}$ & 309 & 181 \\
\hline & & & & $47.6^{\circ} \mathrm{N}$ & 304 & 188 \\
\hline & & & & $45.3^{\circ} \mathrm{N}$ & 311 & 193 \\
\hline \multirow{3}{*}{ East Asia } & 9 & 8 th & $18: 00 \sim 19: 36$ & $28.6^{\circ} \mathrm{N}$ & 551 & 198 \\
\hline & 10 & 9th & $20: 00 \sim 23: 00$ & $28.6^{\circ} \mathrm{N}$ & 508 & 210 \\
\hline & 11 & 10 th & $18: 00 \sim 20: 00$ & $28.6^{\circ} \mathrm{N}$ & 524 & 200 \\
\hline
\end{tabular}

mean horizontal phase velocities of LSTIDs observed in Europe $\left(381 \pm 69 \mathrm{~m} \mathrm{~s}^{-1}\right)$ and North America $\left(422 \pm 36 \mathrm{~m} \mathrm{~s}^{-1}\right)$ were obviously slower than those observed in East Asia $\left(527 \pm 21 \mathrm{~m} \mathrm{~s}^{-1}\right)$, which would be mainly caused by latitude differences between these sectors. According to Mayr et al. (1990) low-speed LSTIDs suffered more energy attenuation as a result of ion drag, molecular viscosity, and thermal diffusivity during their propagation, preventing them from arriving at lower latitudes. Hence low-speed LSTIDs were more frequently observed in Europe and North America, as the geomagnetic latitude of East Asia was lower than that of Europe and North America.

Shiokawa et al. (2003) detected a LSTID that moved equatorward with a horizontal phase velocity of $\sim 600 \mathrm{~m} \mathrm{~s}^{-1}$ during the major magnetic storm of 31 March 2001 in Japan, with the ground-based stations located in the latitude range of $45.4^{\circ} \mathrm{N} \sim 21.2^{\circ} \mathrm{N}$. Hayashi et al. (2010) used the Super Dual Aural Radar Network (SuperDARN) Hokkaido radar combined with the TEC data from the GPS Earth Observation Network (GEONET) to study the LSTIDs on 15 December 2006 in Japan, and found two LSTIDs events prop- agated southward with horizontal phase velocities between 600 and $850 \mathrm{~m} \mathrm{~s}^{-1}$ in the latitudes between $45^{\circ} \mathrm{N}$ and $25^{\circ} \mathrm{N}$. Ding et al. (2007) investigated the LSTIDs during the magnetic super storm of 29 30 October 2003 by global GPS system. They found two LSTIDs over North America in the range of $50^{\circ} \mathrm{N} \sim 30^{\circ} \mathrm{N}$ with horizontal phase velocity of $270 \sim 500 \mathrm{~m} \mathrm{~s}^{-1}$. These findings also indicated that the LSTIDs discovered at low latitudes in Japan propagated faster than the LSTIDs did at high latitudes in North America, which was in reasonable agreement with our results.

\subsection{Damping of LSTIDs}

We have checked the damping rate of LSTIDs and presented the results in different sectors and at different local times in Table 3.

As can be seen in Table 3, both in North America and Europe, the daytime damping rates were larger than the nighttime ones. The average damping rate in daytime was more than 2 times larger than the counterpart at nighttime in Europe, and in North America the daytime average damping rate was about 1.7 times larger than the nighttime one. 

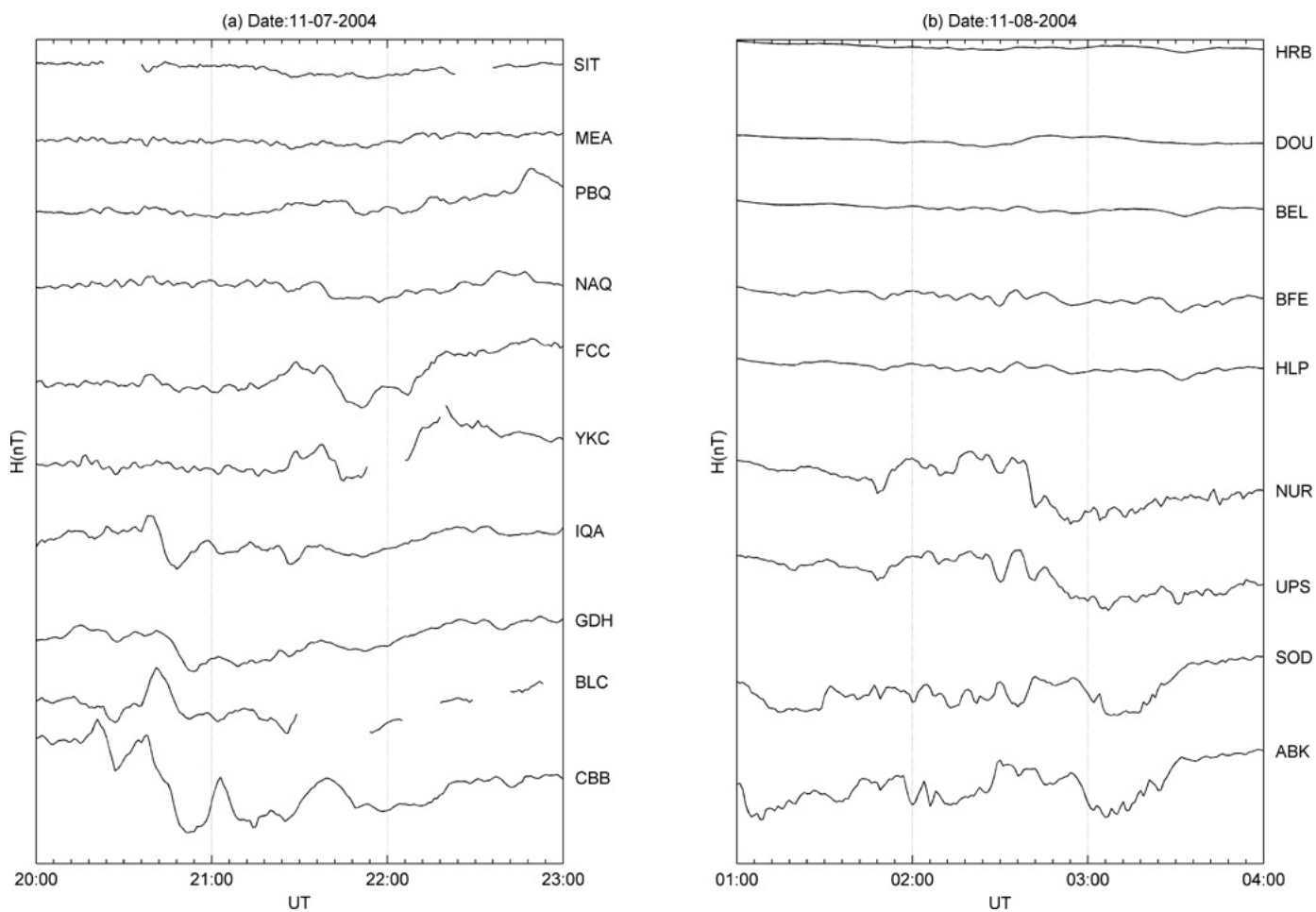

Fig. 6. Time dependence of the magnetic H component during 20:00 23:00 UT on 7 November in North America (a) and 01:00 04:00 UT on 8 November in Europe (b) at the geomagnetic observatories, respectively. The code name of each geomagnetic observatory was marked nearby.

Table 3. The damping rates of the LSTIDs detected in the three sectors on $7 \sim 10$ November 2004 .

\begin{tabular}{lccc}
\hline Sector & Date & LT & Damping rate $\left(10^{-2} \mathrm{~km}\right)$ \\
\hline \multirow{3}{*}{ North } & 7th & $13: 00 \sim 14: 30$ & 0.031 \\
America & 8th & $18: 00 \sim 19: 30$ & 0.014 \\
& 10th & $04: 20 \sim 06: 00$ & 0.016 \\
& 7th & $0.00 \sim 04: 00$ & 0.025 \\
Europe & 8th & $21: 00 \sim 22: 25$ & 0.011 \\
& 9 th & $15: 00 \sim 17: 00$ & 0.013 \\
& 10 th & $12: 00 \sim 14: 00$ & 0.030 \\
East Asia & 9th & $18: 00 \sim 19: 36$ & 0.021 \\
& 10th & $18: 00 \sim 20: 00 \sim 23: 00$ & 0.028 \\
\hline
\end{tabular}

However, the LSTIDs detected in East Asia during this magnetic storm time were all at nighttime, so we did not take this sector into consideration.

Previous ionospheric studies (e.g. Klostermeyer, 1969; Liu and Yeh, 1969; Hines and Hooke, 1970; Yeh et al., 1975; Hajkowicz, 1991; Tsugawa et al., 2003, 2004) have shown that the relative amplitude of LSTIDs rapidly decreased as the LSTIDs propagated from high to middle latitudes. Ac- cording to these studies, the attenuation of the LSTIDs was caused by several factors, such as ion drag, molecular viscosity, thermal conductivity, electric field, and neutral wind. Tsugawa et al. (2003) suggested that the damping of the LSTIDs was caused mainly by the ion drag effect which was proportional to the ion collision frequency. This may explain why the daytime damping rates were larger than the nighttime ones. Since the ion drag was proportional to the collision frequency between ions and the neutrals, the particularly strong ion drag during the daytime due to the increased ionization density of the F region may cause the enhancement of the ion drag and lead to the strong attenuation of LSTIDs in daytime.

\subsection{Source regions of LSTIDs}

Previous researchers (e.g. Hunsucker, 1982; Hajkowicz, 1991) revealed that the possible source regions of LSTIDs were most likely to be located around the auroral region. Hunsucker (1982) pointed out that the enhancement of westward electric current excited atmospheric gravity waves (AGWs) and LSTIDs through the enhancement of Lorentz force and Joule heating. Hajkowicz (1991) reported that a high degree of correlation existed between the auroral electrojet and the LSTIDs with the highest correlation coefficient reaching 0.9 . Therefore, we could use the magnetic field data 
to investigate the possible source regions of the LSITDs during this storm time.

We used the magnetic field data from 10 geomagnetic observatories in North America and 9 in Europe to investigate the possible source regions of the LSTIDs in these two sectors. Source regions of the LSITDs in East Asia were not investigated because of the sparse distributions of geomagnetic observatories in this sector. The locations and codes of all the 19 geomagnetic observatories were plotted as triangles in Fig. 1. We got the time dependence of the magnetic $\mathrm{H}$ component at those 19 geomagnetic observatories between 7 and 10 November 2004. In this paper, we only showed the two of these time series. Figure 6 presented the time dependence of the magnetic $\mathrm{H}$ component during 20:00 23:00 UT on 7 November in North America (Fig. 6a) and 01:00 04:00 UT on 8 November in Europe (Fig. 6b), respectively.

As shown in Fig. 6a, after the onset of the storm at 20:00 UT on 7 November, the magnetic field $\mathrm{H}$ component started decreasing at 20:36 UT at IQA (MLAT: $72.4^{\circ} \mathrm{N}$ ). The LSTID with the horizontal velocity of $422 \pm 36 \mathrm{~m} \mathrm{~s}^{-1}$ was observed $24 \mathrm{~min}$ after the decrease of $\mathrm{H}$ component at IQA. The north edge of the region where the LSTID was observed was around geomagnetic latitude $56^{\circ} \mathrm{N}$, so the source region of this LSTID may be located within $650 \mathrm{~km}$ to the north of $56^{\circ}$ N. Similarly, in Europe, from Fig. 6b we roughly estimated that the source region of the LSTID observed on 8 November was located around geomagnetic latitude $57^{\circ} \mathrm{N}$.

We analyzed the possible source regions of all the LSTIDs we detected in North America and Europe. The source regions of the LSTIDs in North America were likely to be located between geomagnetic latitudes $68^{\circ} \mathrm{N}$ and $62^{\circ} \mathrm{N}$, while in Europe the possible range of the source regions was between geomagnetic latitudes $65^{\circ} \mathrm{N}$ and $57^{\circ} \mathrm{N}$.

\section{Conclusions}

In this paper we have analyzed the global propagation features of the LSTIDs during the magnetic super storm on 7 10 November 2004, by using the GPS TEC data provided by the Scripps Orbit and Permanent Array Center (SOPAC) and IGS. During this period, 11 LSTIDs events were detected, which were temporally well-correlated with the occurrence of auroral substorms. The results can be summarized as follows.

1. The propagation azimuths of LSTIDs were dependent on latitudes. The lower geomagnetic latitudes the LSTIDs arrived the more they deflected to the west from south. This may indicate that the effect of the Coriolis force on the propagation of LSTIDs was one of the main causes of their southwestward deviation.

2. The mean horizontal phase velocities were different among different sectors. The mean horizontal phase ve- locities of the LSTIDs observed at low geomagnetic latitudes $\left(527 \pm 21 \mathrm{~m} \mathrm{~s}^{-1}\right.$ in East Asia) were higher than those observed at high geomagnetic latitudes (422 \pm $36 \mathrm{~m} \mathrm{~s}^{-1}$ in North America and $381 \pm 69 \mathrm{~m} \mathrm{~s}^{-1}$ in Europe). Due to the fact that slow velocity TIDs dissipated more quickly than the high velocity ones did during their propagation, so high velocity LSTIDs were more frequently to be detected at lower geomagnetic latitudes.

3. The damping rate of the LSTIDs was also different in terms of local time. The damping rate of daytime LSTIDs was larger than the nighttime one. Our results showed that the variation of damping rate was mainly caused by the variation of ion drag, which was higher in the daytime than at nighttime.

4. The possible source regions of the LSTIDs detected in North America and Europe during this magnetic storm was roughly estimated by analyzing the $\mathrm{H}$ component of the magnetic field at 19 geomagnetic observatories. The source regions of the LSTIDs in North America were likely to be located between geomagnetic latitudes of $68^{\circ} \mathrm{N}$ and $62^{\circ} \mathrm{N}$, and in Europe the possible range of the source regions was between geomagnetic latitudes of $65^{\circ} \mathrm{N}$ and $57^{\circ} \mathrm{N}$.

Acknowledgements. We are grateful to the Scripps Orbit and Permanent Array Center (SOPAC) and IGS for providing GPS network data via the Internet. This work was supported by the Chinese Academy of Sciences(KZZD-EW-01-2,KZZD-EW-01-3), National Natural Science Foundation of China (grants 40974089, 41131066), and the National Key Basic Research Program of China (2011CB811405).

Topical Editor K. Kauristie thanks T. Tsugawa and another anonymous referee for their help in evaluating this paper.

\section{References}

Afraimovich, E. L. and Voeykov, S. V.: Experimental evidence of the existence of a solitary internal gravity wave in the Earth's atmosphere during a strong magnetic storm, Dokl. Earth. Sci., 399, 683-686, 2004.

Afraimovich, E. L., Kosogorov, E. A., and Leonovich, L. A.: Determining parameters of large-scale traveling ionospheric disturbances of auroral origin using GPS-arrays, J. Atmos. Solar Terr. Phys., 62, 553-565, 2000.

Afraimovich, E. L., Bashkuev, Yu. B., Berngardt, O. I., Gatsutsev, A. V., Dembelov, M. G., Shpynev, B. G., Kobzar, V. A., Kushnarev, D. S., Musin, V. Yu., Pushkin, P. Yu., and Perevalova. N. P.: Detection of travelling ionospheric disturbances from the data of simultaneous measurements of the electron concentration, total electron content, and Doppler frequency shift at the ISTP radiophysical complex, Geomagn. Aeronomy., 44, 463475, 2004.

Afraimovich, E. L., Buzevich, A. V., and Zhivet'ev, I. V.: Largescale traveling ionospheric disturbances during the large magnetic storm of October 29-30, 2003, according to data of the 
Kamchatka network of GPS stations, Geomagn. Aeronomy., 45, 118-121, 2005.

Ding, F., Yuan, H., Wan, W., Reid, I. M., and Woithe, J. M.: Occurrence characteristics of medium-scale gravity waves observed in $\mathrm{OH}$ and $\mathrm{OI}$ nightglow over Adelaide $\left(34.5^{\circ} \mathrm{S}, 138.5^{\circ} \mathrm{E}\right)$, J. Geophys. Res., 109, D14104, doi:10.1029/2003JD004096, 2004.

Ding, F., Wan, W., Ning, B., and Wang, M.: Large-scale traveling ionospheric disturbances observed by GPS total electron content during the magnetic storm of 29-30 October 2003, J. Geophys. Res., 112, A06309, doi:10.1029/2006JA012013, 2007.

Ding, F., Wan, W., Liu, L., Afraimovich, E. L., Voeykov, S. V., and Perevalova, N. P.: A statistical study of large-scale traveling ionospheric disturbances observed by GPS TEC during major magnetic storms over the years 2003-2005, J. Geophys. Res., 113, A00A01, doi:10.1029/2008JA013037, 2008.

Hajkowicz, L. A.: A global study of large scale traveling ionospheric disturbances (TIDs) following a step-like onset of auroral substorms in both hemispheres, Planet Space Sci., 38, 913-923, 1990.

Hajkowicz, L. A.: Global onset and propagation of large-scale traveling ionospheric disturbances as a result of the great storm of 13 March 1989, Planet. Space Sci., 39, 583-593, 1991.

Hayashi, H., Nishitani, N., Ogawa, T., Otsuka, Y., Tsugawa, T., Hosokawa, K., and Saito, A.: Large-scale traveling ionospheric disturbance observed by superDARN Hokkaido HF radar and GPS networks on 15 December 2006, J. Geophys. Res., 115, A06309, doi:10.1029/2009JA014297, 2010.

Hines, C. O. and Hooke, W. H.: Discussion of ionization effects on the propagation of acoustic-gravity waves in the ionosphere, J. Geophys. Res., 75, 2563-2568, 1970.

Hocke, K. and Schlegel, K.: A review of atmospheric gravity waves and travelling ionospheric disturbances: 1982-1995, Ann. Geophys., 14, 917-940, doi:10.1007/s00585-996-0917-6, 1996.

Hunsucker, R. D.: Atmospheric gravity waves generated in the high latitude ionospheric: A review, Rev. Geophys., 20, 293-315, 1982.

Klostermeyer, J.: Gravity waves in the F-region, J. Atmos.Terr. Phys., 31, 25-45, 1969.

Kotake, N., Otsuka, Y., Ogawa, T., Tsugawa, T., and Saito, A.: Statistical study of medium-scale traveling ionospheric disturbances observed with the GPS networks in Southern California, Earth Planets Space, 59, 95-102, 2007.

Leonovich, L. A., Afraimovich, E. L., and Portnyagina, O. G.: Velocity and direction of the displacement of TEC large-scale traveling ionospheric disturbances during strong magnetic storms, Geomagn. Aeronomy., 44, 149-155, 2004.

Liu, C. H. and Yeh, K. C.: Effect of ion drag on propagation of acoustic-gravity waves in the atmospheric F region, J. Geophys. Res., 74, 2248-2255, 1969.

Mayr, H. G., Harris, I., Herrero, F. A., Spencer, N. W., Varosi, F., and Pesnell, W. D.: Thermospheric gravity waves: Observations and interpretation using the transfer function model (TFM), Space Sci. Rev., 54, 297-375, doi:10.1007/BF00177800, 1990.
Nicolls, M. J., Kelley, M. C., Coster, A. J., González, S. A., and Makela, J. J.: Imaging the structure of a large-scale TID using ISR and TEC data, Geophys. Res. Lett., 31. L09812, doi:10.1029/2004GL019797, 2004.

Rice, D. D., Hunsucker, R. D., Lanzerotti, L. J., Crowley, G., Williams, P. J. S., Craven, J. D., and Frank, L.: An observation of atmospheric gravity wave cause and effect during the October 1985 WAGS campaign, Radio Sci., 23, 919-930, doi:10.1029/RS023i006p00919, 1988.

Saito, A., Nishimura, M., and Yamamoto, M.: Traveling ionospheric disturbances detected in the FRONT campaign, Geophys. Res. Lett., 28, 689-692, 2001.

Sardón, E. and Zarraoa, N.: Estimation of total electron content using GPS data: How stable are the differential satellite and receiver instrumental biases?, Radio Sci., 32, 1899-1910, 1997.

Shiokawa, K., Otsuka, Y., Ogawa, T., Balan, N., Igarashi, K., Ridley, A. J., Knipp, D. J., Saito, A., and Yumoto, K.: A large-scale traveling ionospheric disturbance during the magnetic storm of 15 September 1999, J. Geophys. Res., 107, 1088, doi:10.1029/2001JA000245, 2002.

Shiokawa, K., Otsuka, T., Ogawa, T., Kawamura, S., Yamamoto, M., Fukao, S., Nakamura, T., Tsuda, T., Balan, N., Igarashi, K., Lu, G., Saito, A., and Yumoto, K.: Thermospheric wind during a storm-time large-scale traveling ionospheric disturbance, J. Geophys. Res., 108, 1423, doi:10.1029/2003JA010001, 2003.

Strand, O. N.: Multichannel complex maximum entropy (autoregressive) spectral analysis, IEEE T. Automat. Contr., 22, 634640, 1977.

Tsugawa, T., Saito, A., Otsuka, Y., and Yamamoto, M.: Damping of large-scale traveling ionospheric disturbances detected with GPS networks during the geomagnetic storm, J. Geophys. Res., 108, 1127, doi:10.1029/2002JA009433, 2003.

Tsugawa, T., Saito, A., and Otsuka, Y.: A statistical study of large-scale traveling ionospheric disturbances using the GPS network in Japan, J. Geophys. Res., 109, A06302, doi:10.1029/2003JA010302, 2004.

Tsugawa, T., Shiokawa, K., and Otsuka, Y.: Geomagnetic conjugate observations of large-scale traveling ionospheric disturbances using GPS networks in Japan and Australia, J. Geophys. Res., 111, A02302, doi:10.1029/2005JA011300, 2006.

Tsugawa, T., Otsuka, Y., Coster, A. J., and Saito, A.: Mediumscale traveling ionospheric disturbances detected with dense and wide TEC maps over North America, Geophys. Res. Lett., 34, L22101, doi:10.1029/2007GL031663, 2007.

Wan, W., Ning, B., Yuan, H., Li, J., Li, L., and Liang, J.: TID observation using a short baseline network of GPS receivers, Acta Geod. Geophys. Hu., 32, 321-327, 1997.

Yeh, K. C., Liu, C. H., and Youakim, M. Y.: Attenuation of internal gravity waves in model atmospheres, Ann. Geophys., 31, 321328, 1975.

Zhang, D. H., Zhang, W., Li, Q., Shi, L. Q., Hao, Y. Q., and Xiao, Z.: Accuracy analysis of the GPS instrumental bias estimated from observations in middle and low latitudes, Ann. Geophys., 28, 1571-1580, doi:10.5194/angeo-28-1571-2010, 2010. 